\section{Comparison of the Phenolic Profiles of Juice and Cider Derived from Machine- and Hand-harvested 'Brown Snout' Specialty Cider Apples in Northwest Washington}

\author{
Travis R. Alexander ${ }^{1,3}$, Thomas S. Collins ${ }^{2}$, and Carol A. Miles ${ }^{1}$
}

ADDITIONAL INDEX wORDs. catechin equivalents, labor, Malus $\times$ domestica, mass spectrometry, sweating, shake-and-catch

Summary. 'Brown Snout' cider apple (Malus $\times$ domestica) is desired by cider makers for its relatively high levels of phenolics, and over-the-row machine harvesting of 'Brown Snout' has been demonstrated to provide similar yield to hand harvest at a significantly lower cost. The purpose of this study was to determine if there is a measurable impact of harvest method on the phenolic profile of 'Brown Snout' juice and cider to better inform equipment adoption recommendations. Using a redox titration assay, the titratable tannin content $( \pm$ SE $)$ of juice $(0.19 \% \pm 0.01 \%)$ and cider $(0.19 \% \pm 0.01 \%)$ were found not to differ due to harvest method. Using a protein precipitation assay, juice from machine-harvested fruit was found to have lower levels of total tannins $\left[231 \pm 36 \mathrm{mg} \cdot \mathrm{L}^{-1}\right.$ catechin equivalents $\left.(\mathrm{CE})\right]$ than juice from hand-harvested fruit $\left(420 \pm 14 \mathrm{mg} \cdot \mathrm{L}^{-1} \mathrm{CE}\right)$. However, the total tannins of cider did not differ due to harvest method, the overall average for machine and hand harvest was $203 \pm 22 \mathrm{mg} \cdot \mathrm{L}^{-1} \mathrm{CE}$. The total phenolics of juice and cider did not differ due to harvest method $\left(1415 \pm 98 \mathrm{mg} \cdot \mathrm{L}^{-1} \mathrm{CE}\right.$ and $1431 \pm 73 \mathrm{mg} \cdot \mathrm{L}^{-1} \mathrm{CE}$, respectively). Discriminant analysis based on an average of 33 tentatively identified phenolic compounds, as measured by ultra-high performance liquid chromatography coupled with quadrupole time of flight mass spectrometry, showed no separation due to harvest method in juice or cider. In conclusion, over-the-row machine harvesting of 'Brown Snout' resulted in a final product of similar quality at reduced labor costs, and thus shows potential for increasing the commercial sustainability of cider apple operations.

$\mathrm{P}$ henolics are secondary metabolites that contribute significantly to the sensory profile of fermented cider, especially in those ciders made from cider apple fruit. Phenolics can impact the pressing of fruit, the clarification of juice, the maturation of cider, and final cider

Received for publication 27 Mar. 2019. Accepted for publication 17 May 2019

Published online 28 June 2019.

We thank Ed Scheenstra, Saul Phillips, Garrett Lattanzio, Rosemary Veghte, and Maria Mireles for their contributions to the completion of this work. This research was supported in part by Washington State Department of Agriculture Specialty Block Grant Project No. K1270, Washington State Projects 1000194 and 1016366, and Washington State University Emerging Research Issues Grant \#15-01-02.

${ }^{1}$ Washington State University Mount Vernon Northwestern Washington Research and Extension 7 Center, 16650 State Route 536, Mount Vernon, WA 98273

${ }^{2}$ Washington State University Wine Science Center, University Drive, Richland, WA 99354

${ }^{3}$ Corresponding author. E-mail: travis.alexander@ wsu.edu.

This is an open access article distributed under the CC BY-NC-ND license (https://creativecommons.org/ licenses/by-nc-nd/4.0/).

https://doi.org/10.21273/HORTTECH04342-19 quality, including the attributes of aroma, color, taste, and mouthfeel (Lea, 1990; Whiting, 1975). English and French cider apple cultivars have historically been classified based on the titratable acidity and titratable tannin contents of their respective musts (Barker, 1903; Tavernier and Jacquin, 1949). Polyphenols also provide protective health benefits via their antioxidant capacity, and regular polyphenol consumption is associated with decreased incidences of chronic diseases such as heart failure and diabetes (Tomas-Barberan and AndresLacueva, 2012).
The main classes of phenolic compounds present in cider apples are procyanidins [predominantly polymers of (-)-epicatechin (Sanoner et al., 1999)], phenolic acids (primarily chlorogenic acid and pcoumaroylquinic acid), and flavonoids (such as phloridzin and phloretin) (Guyot et al., 2003). Procyanidins specifically underlie the tactile sensation of astringency and the taste sensation of bitterness, and their degree of polymerization underlies relative perception of these sensory attributes (Lea and Arnold, 1978). Astringency in cider is the product of hydrogen bonding between procyanidins and proteins of the tongue, and perception of astringency increases with the capacity for hydrogen bonding (i.e., with larger-sized procyanidins) (Joslyn and Goldstein, 1964). Bitterness is the product of procyanidin polar moieties binding with taste receptors in the papillae membranes of the tongue, and perception generally decreases with time (a process commonly termed softening) (Koyama and Kurihara, 1972). Lea and Arnold (1978) observed that ethanol, in comparison with pure water, enhanced response to bitterness while it suppressed response to astringency.

The polyphenol composition of cider apples has been found to vary with cultivar, maturity of fruit, fruit storage, fruit tissue, and region of production (Alwood, 1903; Ewing et al., 2019; Nicolas et al., 1994; Thompson-Witrick et al., 2014). Composition has also been found to vary with pressing method, including factors such as equipment, time, and temperature (Renard et al., 2011). During the crushing and pressing of fruit, previously compartmentalized and separated components can interact, and polyphenol composition in the fruit can be significantly transformed in the juice. Transformations

\begin{tabular}{llll}
\hline $\begin{array}{l}\text { Units } \\
\text { To convert U.S. to SI, } \\
\text { multiply by }\end{array}$ & U.S. unit & SI unit & $\begin{array}{l}\text { To convert SI to U.S., } \\
\text { multiply by }\end{array}$ \\
\hline 29.5735 & $\mathrm{fl} \mathrm{oz}$ & $\mathrm{mL}$ & 0.0338 \\
0.3048 & $\mathrm{ft}$ & $\mathrm{m}$ & 3.2808 \\
3.7854 & $\mathrm{gal}$ & $\mathrm{L}$ & 0.2642 \\
25.4 & inch $(\mathrm{es})$ & $\mathrm{mm}$ & 0.0394 \\
0.4536 & $\mathrm{lb}$ & $\mathrm{kg}$ & 2.2046 \\
1 & $\mathrm{micron}(\mathrm{s})$ & $\mu \mathrm{m}$ & 1 \\
0.001 & $\mathrm{ppm}$ & $\mathrm{g} \cdot \mathrm{kg}$ & 1000 \\
0.001 & $\mathrm{ppm}$ & $\mathrm{g} \cdot \mathrm{L}^{-1}$ & 1000 \\
1 & $\mathrm{ppm}$ & $\mathrm{mg} \cdot \mathrm{L}^{-1}$ & 1 \\
$\left({ }^{\circ} \mathrm{F}-32\right) \div 1.8$ & ${ }^{\circ} \mathrm{F}$ & ${ }^{\circ} \mathrm{C}$ & $\left({ }^{\circ} \mathrm{C} \times 1.8\right)+32$
\end{tabular}


of phenolic compounds include modifications via enzymatic browning and precipitation (Cliff et al., 1991; Lea and Timberlake, 1978; Sataque and Wosiacki, 1987). Guyot et al. (2003) found concentrations of monomeric catechins and procyanidins to be significantly decreased in five French cider apple cultivars as a result of oxidation during crushing and/or interactions with solid material that were induced by the oxidative conditions. Addition of agents such as ascorbic acid and sulfur dioxide can act to counter these compositional changes (Shahidi and Naczk, 1995). An optimum concentration of phenolics in cider apple juice has not yet been established, and the lack of a standard commercial protocol for producing cider makes it challenging to determine such a threshold. At the same time, the quality of phenolics present is as important as the quantity.

In the current study, the polyphenol profiles of juice and cider derived from machine- and handharvested 'Brown Snout' specialty cider apples were compared as part of an overall proof of concept project designed to respond to uncertainty in harvest labor availability and affordability (Thilmany, 2001). Using an over-the-row small fruit harvester (model OR0012; Littau Harvester, Stayton, OR), Washington State University (WSU) researchers have demonstrated a reduction in total harvest cost, up to $22 \%$, relative to hand harvest (Galinato et al., 2016), with a negligible impact to juice quality at harvest or after 1 month of cold storage of the fruit $\left[3.3{ }^{\circ} \mathrm{C}\right.$ (Miles and King, 2014)]. The calculated reduction cost included the approximate rental rate for the machine harvester, as the equipment most likely is too expensive for the average cider apple orchard (less than 8 acres in the Pacific northwest United States) to purchase. Juice quality was evaluated by WSU researchers in terms of five characteristics deemed important by cider apple growers and cider makers: soluble solids concentration, specific gravity, $\mathrm{pH}$, titratable acidity, and titratable tannic acid. The analysis of titratable tannin content was pursuant to the standard method (Löwenthal) used at the Long Ashton Research Station since 1903 (Löwenthal, 1877). Although results of this method, a general measure of oxidizable matter, have correlated well with the perception of astringency and the ripeness of fruit (Soest, 1994), it does not provide quantitative differences in phenolic compounds.

Previous research has demonstrated a difference in the sensory profiles of ciders produced from machine- and hand-harvested 'Brown Snout', as perceived by a trained panel and an electronic tongue ( $\alpha$-ASTREE II; Alpha MOS Co., Toulouse, France) (Alexander et al., 2018). The machineharvested samples were more astringent, as evaluated by the trained panel, and less bitter, as evaluated by the electronic tongue, than the hand-harvested samples, which was in line with researchers' expectations. As explained previously, the physical damage imparted by mechanical harvest results in fruit that is vulnerable to physiochemical interactions that include the binding and polymerization of phenolics, which results in a less bitter but more astringent sensory perception (Guyot et al., 2003; Lea, 1990; Nicolas et al., 1994; Renard et al., 2001).

In 2017, multiple analytical approaches were used to identify and quantify potential phenolic differences in juice and cider produced from machine- and hand-harvested 'Brown Snout' that was ambient stored $\left(56{ }^{\circ} \mathrm{F}\right)$ for 0,2 , and 4 weeks postharvest in 2016. Ambient storage, such as in a barn, is a common practice among cider apple growers who have traditionally not had the financial capacity to access either modified or controlled atmosphere storage facilities. There does not exist an assay that can alone quantify and qualify every phenolic compound known, and therefore multiple assays were performed to achieve a complete data set and to allow for comparison of methodologies. It was expected that the total phenolics of juice and cider would not differ due to harvest method, but the total tannins of juice and cider may differ with longer storage times because they allow for greater oxidation and polymerization to occur in the significantly more bruised machine-harvested fruit.

\section{Materials and methods}

Trees. Eight main plots consisting of an average of nine trees each were planted in 2002 at WSU Northwestern Washington Research and Extension Center in Mount Vernon.
'Brown Snout' grafted on one of two rootstocks, 'Malling-27' or 'East Malling Long Ashton-9', was planted in Skagit silt loam, a fine-silty, mixed, nonacid, mesic Typic Fluvaquent (U.S. Department of Agriculture, 2013). To accommodate the machine-harvest treatment, trees were planted at $16 \mathrm{ft}$ between-row and 4 $\mathrm{ft}$ in-row, trained to a three-wire trellis system with the lowest wire 2 $\mathrm{ft}$ above the soil surface, and pruned to a maximum height of $6.5 \mathrm{ft}$. Trees were fertilized and sprayed pursuant to regional commercial recommendations (Moulton and King, 2008; Washington State University, 2013).

Juice. In 2016, 'Brown Snout' was harvested when fully ripe, using a combination of harvest metrics [black seed coloring, average soluble solids concentration reading of $13.5 \%$, and an 8 out of 9 starch index value (BC/Ontario starch index) (Blanpied and Silsby, 1992; Chu and Wilson, 2000)]. Two harvest methods, hand harvest by four relatively unskilled agricultural workers (common in a region that lacks a highly trained labor force) and machine harvest by an over-the-row small fruit harvester (model OR0012; Littau Harvester, Stayton, OR), were randomly applied to the eight main plots such that each harvest method was replicated four times. Rootstock effect was pooled together because Miles and King (2014) demonstrated juice quality was unaffected by rootstock, and this previous work involved the same rows of trees. For both harvest methods, fruit was collected in polyethylene grape boxes. When application of the two harvest method treatments was complete, three filled grape boxes (average 40 $\mathrm{lb} / \mathrm{box}$ ) were selected from each of the harvested main plots for application of the subplot factor of duration of ambient storage $\left[56{ }^{\circ} \mathrm{F}\right.$ (Hobo U12 4-channel; Onset Computer Corp., Bourne, MA)]. One of three boxes was stored postharvest for 0 weeks, one was stored for 2 weeks, and one was stored for 4 weeks. The study had a split-plot design with main plots arranged in a completely randomized design, with the main plot factor of harvest method having two levels and the subplot factor of duration of ambient storage having three levels. At the completion of each storage period, the respective 
Table 1. Specific gravity (SG), alcohol by volume (ABV), pH, titratable acidity (TA), and titratable tannin (TTannin) of juice and cider derived from machine- and hand-harvested 'Brown Snout' cider apples ambient stored [ $\left.56{ }^{\circ} \mathrm{F}\left(13.3{ }^{\circ} \mathrm{C}\right)\right]^{\circ}$ postharvest 0,2 , or 4 weeks in Washington in 2016. Data are combined for harvest methods, as no significant variation was attributable to the main factor for any of the parameters.

\begin{tabular}{|c|c|c|c|c|c|}
\hline \multirow{2}{*}{$\begin{array}{l}\text { Duration ambient } \\
\text { storage (weeks) }\end{array}$} & $S^{z}$ & ABV (\%) & $\mathrm{pH}^{\mathrm{z}}$ & $\begin{array}{c}\text { TA (malic acid } \\
\text { equivalents) }\end{array}$ & $\begin{array}{l}\text { TTannin (tannic } \\
\text { acid equivalents) }\end{array}$ \\
\hline & \multicolumn{5}{|c|}{$($ mean $\pm S E)$} \\
\hline 0 & $1.054 \pm 0.001 \mathrm{~b}^{\mathrm{y}}$ & $0 \pm 0$ & $4.07 \pm 0.01 \mathrm{~b}$ & $0.35 \pm 0.01 \mathrm{~b}$ & $0.19 \pm 0.01$ \\
\hline 2 & $1.057 \pm 0.001 \mathrm{ab}$ & $0 \pm 0$ & $4.06 \pm 0.01 \mathrm{~b}$ & $0.35 \pm 0.01 b$ & $0.19 \pm 0.01$ \\
\hline 4 & $1.059 \pm 0.001 \mathrm{a}$ & $0 \pm 0$ & $\begin{array}{c}4.01 \pm 0.01 \mathrm{a} \\
\text { Cider }\end{array}$ & $0.38 \pm 0.01 \mathrm{a}$ & $0.19 \pm 0.01$ \\
\hline 2 & $0.999 \pm 0.000$ & $5.61 \pm 0.18 \mathrm{ab}$ & $3.52 \pm 0.01$ & $0.62 \pm 0.02$ & $0.19 \pm 0.01$ \\
\hline 4 & $0.999 \pm 0.000$ & $6.14 \pm 0.16 \mathrm{a}$ & $3.52 \pm 0.01$ & $0.64 \pm 0.01$ & $0.19 \pm 0.01$ \\
\hline
\end{tabular}

${ }^{\mathrm{z}}$ Dimensionless quantity.

${ }^{\mathrm{y}}$ Means within a column followed by a different letter are significantly different $(P<0.05)$, as determined by Tukey's honestly significant difference test.

filled grape boxes were sorted, rotted fruit was discarded, and the remaining fruit was milled (MultiMax 30; Zambelli Enotech, Camisano Vicentino, Italy) and pressed (Carezza; Enotecnica Pillan, Camisano Vicentino, Italy). Greater rotting was observed in the machine-harvested crates than handharvested crates (on average $4 \%$ and $0 \%$, respectively), and doubled from 2 to 4 weeks of ambient storage for the machine-harvest treatment [ $4 \%$ to $8 \%$ (data not shown)]. Juice was collected in separate 1-gal polyethylene jugs (ULINE, Pleasant Prairie, WI) and frozen at $5^{\circ} \mathrm{F}$ until such time that all samples had been collected and prepared for subsequent fermentation. A $50-\mathrm{mL}$ aliquot of juice was also collected in polypropylene centrifuge tubes (Sycamore Life Sciences, Houston, TX) and frozen at $5^{\circ} \mathrm{F}$ until such time that all samples had been collected for subsequent chemical analyses.

Cider. When application of the three storage duration treatments was complete and the respective crates of fruit were processed, the frozen 1-gal plastic jugs of juice were thawed to $68{ }^{\circ} \mathrm{F}$. Juice was fermented pursuant to a protocol developed from Zimmerman et al. (2017) with the following modifications. Sulfite [potassium metabisulfite (Esseco USA, Parsippany, $\mathrm{NJ}$ )] was added at a dosage of $35 \mathrm{mg} \cdot \mathrm{L}^{-1}$, targeting a molecular sulfur dioxide level of $0.8 \mathrm{mg} \cdot \mathrm{L}^{-1}$ for an average juice $\mathrm{pH}$ of 3.45 . Yeast (DV10; Lallemand, Rexdale, ON, Canada) was hydrated $\left(100 \mathrm{~g} \cdot \mathrm{kg}^{-1}, 104{ }^{\circ} \mathrm{F}\right)$, cooled to the temperature of the juice $\left(68^{\circ} \mathrm{F}\right)$ using two adjustment steps, and the respective 1-gal glass carboys

Table 2. Total phenolics, total tannins, and nontannin phenolics of juice and cider derived from machine- and hand-harvested 'Brown Snout' cider apples ambient stored $\left[56^{\circ} \mathrm{F}\left(13.3^{\circ} \mathrm{C}\right)\right]$ postharvest 0,2 , or 4 weeks in Washington in 2016. Data are combined for duration of ambient storage, as no significant variation was attributable to the subplot factor for any of the parameters.

\begin{tabular}{|c|c|c|c|}
\hline \multirow[b]{2}{*}{ Harvest method } & Total phenolics & Total tannins & Nontannin phenolics ${ }^{\mathrm{z}}$ \\
\hline & \multicolumn{3}{|c|}{$\left[\text { mean } \pm \mathrm{SE}\left(\mathrm{mg} \cdot \mathrm{L}^{-1} \text { catechin equivalents }\right)\right]^{\mathrm{y}}$} \\
\hline & \multicolumn{3}{|c|}{ Juice } \\
\hline Machine & $1,415 \pm 126$ & $231 \pm 36 b^{x}$ & $1,184 \pm 93 a$ \\
\hline Hand & \multicolumn{3}{|c|}{ Cider } \\
\hline Machine & $1,390 \pm 75$ & $191 \pm 19$ & $1,199 \pm 94$ \\
\hline Hand & $1,472 \pm 71$ & $214 \pm 24$ & $1,258 \pm 54$ \\
\hline
\end{tabular}

${ }^{\mathrm{z}}$ Calculated as the difference between total phenolics and total tannins.

${ }^{\mathrm{y}} \mathrm{l} \mathrm{mg} \cdot \mathrm{L}^{-1}=1 \mathrm{ppm}$.

${ }^{\mathrm{x}}$ Means within a column followed by a different letter are significantly different $(P<0.05)$, as determined by Tukey's honestly significant difference test.

(ULINE) of juice were dosed at 0.31 $\mathrm{g} \cdot \mathrm{L}^{-1}$. When specific gravity $(\mathrm{SG})$ readings dropped by one-third of their initial values, on average starting at 1.072 , supplemental yeast nutrients (Fermaid K; Scott Laboratories, Petaluma, CA) were added at a dosage of $0.25 \mathrm{~g} \cdot \mathrm{L}^{-1}$. Fermentation continued at $57^{\circ} \mathrm{F}$ until $S \mathrm{G}$ was equal to or less than $1.000, \approx 2.5$ weeks after being topped. After 5 months of maturation, cider was racked into $12-\mathrm{fl} \mathrm{oz}$ glass bottles (Great Fermentations, Indianapolis, IN), capped, and stored at $57^{\circ} \mathrm{F}$ until they were chemically analyzed, 2 weeks later. Cider was not carbonated, as it can undesirably affect chemical analyses such as measuring of $\mathrm{pH}$. A $50-\mathrm{mL}$ aliquot of cider was also collected in polypropylene centrifuge tubes (Sycamore Life Sciences) and frozen at $5{ }^{\circ} \mathrm{F}$ for subsequent chemical analyses.

QUALITy CHARACTERISTICS ANALYSIS. At the WSU Wine Science
Center in Richland, WA, the frozen 50$\mathrm{mL}$ aliquots of juice and cider were thawed to $68^{\circ} \mathrm{F}$ and then $5 \mathrm{~mL}$ of each collected for measurement of five quality characteristics deemed important by cider apple growers and cider makers. SG and alcohol by volume [ABV (\% v/ v)] were measured by an Alcolyzer ME System (Anton Paar, Graz, Austria). $\mathrm{pH}$ and titratable acidity [TA $(\% \mathrm{w} / \mathrm{v}$ expressed as malic acid)] were measured using an automated titrator (T50; Mettler Toledo, Greifensee, Switzerland). Titratable tannin content $(\% \mathrm{w} / \mathrm{v}$ expressed as tannic acid) was measured using the Löwenthal method.

Total PHENOLICS AND TOTAL TANNins analysis. A 2 -mL sample was collected from the thawed $50-\mathrm{mL}$ aliquots of juice and cider, filtered $(0.45-\mathrm{mm}$ syringe filter; AhlstromMunksjö, Helsinki, Finland) and frozen at $-112{ }^{\circ} \mathrm{F}$ for polyphenol profiling. Total phenolics and total tannins were determined pursuant to 
Harbertson et al. (2003). In general, total phenolics were assayed by diluting each sample 10-fold directly into buffer, adding ferric chloride $\left[\mathrm{FeCl}_{3} ; 0.01 \mathrm{~N}\right.$ hydrogen chloride ( $\left.\mathrm{HCl}) 10 \mathrm{~mm} \mathrm{FeCl}_{3}\right]$ and taking an absorbance reading at $510 \mathrm{~nm}$. Readings were then converted to $\mathrm{CE}$ with a standard curve. Tannin was assayed by first coprecipitating tannins with bovine serum albumin (BVA) at $\mathrm{pH}$ 4.9 , dissolving (1.3-fold) the collected pellet in buffer after centrifugation, adding $\mathrm{FeCl}_{3}$, and taking an absorbance reading at $510 \mathrm{~nm}$. A 5\% $(\mathrm{w} / \mathrm{v})$ sodium dodecyl sulfate $5 \%(\mathrm{v} / \mathrm{v})$ triethanolamine (TEA) buffer was used in place of the prescribed 500 g. $\mathrm{L}^{-1}$ urea $5 \%(\mathrm{v} / \mathrm{v})$ TEA buffer as tannin absorbance values of the cider samples were not in the valid range for analysis when treated with the latter buffer. All chemical reagents were from Thermo Fisher Scientific (Waltham, MA) except for the BVA purchased from Sigma-Aldrich (St. Louis, MO). Absorbance measurements were taken with a ultraviolet-visible spectrophotometer (8453; Agilent Technologies, Santa Clara, CA).

ULTRA-HIGH PERFORMANCE LIQUID CHROMATOGRAPHY / QUADRUPOLE TIME OF FLIGHT MASS SPECTROMETRY ANALYSIS. The phenolic composition of juice and cider samples was analyzed in triplicate using ultra-high performance liquid chromatography (UHPLC) coupled with quadrupole time of flight mass spectrometry (QTOF-MS). UHPLC was performed with a chromatograph (1290 Infinity II; Agilent Technologies) that was equipped with a reverse phase column $[2.1 \times 50 \mathrm{~mm}, 1.8 \mu \mathrm{m}$ particle size (Zorbax Eclipse Plus C18; Agilent Technologies)] and maintained at $140{ }^{\circ} \mathrm{F}$. UHPLC effluent was analyzed using negative mode electrospray ionization coupled to time of flight mass spectrometry on a mass spectrometer (6545; Agilent Technologies). Ionization was performed in negative mode to generate pseudomolecular parent ions $[\mathrm{M}-\mathrm{H}]^{-}$of compounds to be present in the samples. Juice was filtered (0.45 $\mu \mathrm{m}$ syringe filter; AhlstromMunksjö) and diluted (2:1) with ultrapure water (Milli-Q; MilliporeSigma, Boston, MA) to reduce the concentration of sugars in the samples, as undiluted juice initially caused malfunction of the autosampler due to a buildup of sugar. Cider samples were filtered as for juices, but were not diluted.
Statistical ANALYsis. Data were expressed as mean \pm SE for $n=4$ replicates for $\mathrm{pH}, \mathrm{SG}, \mathrm{TA}$, total
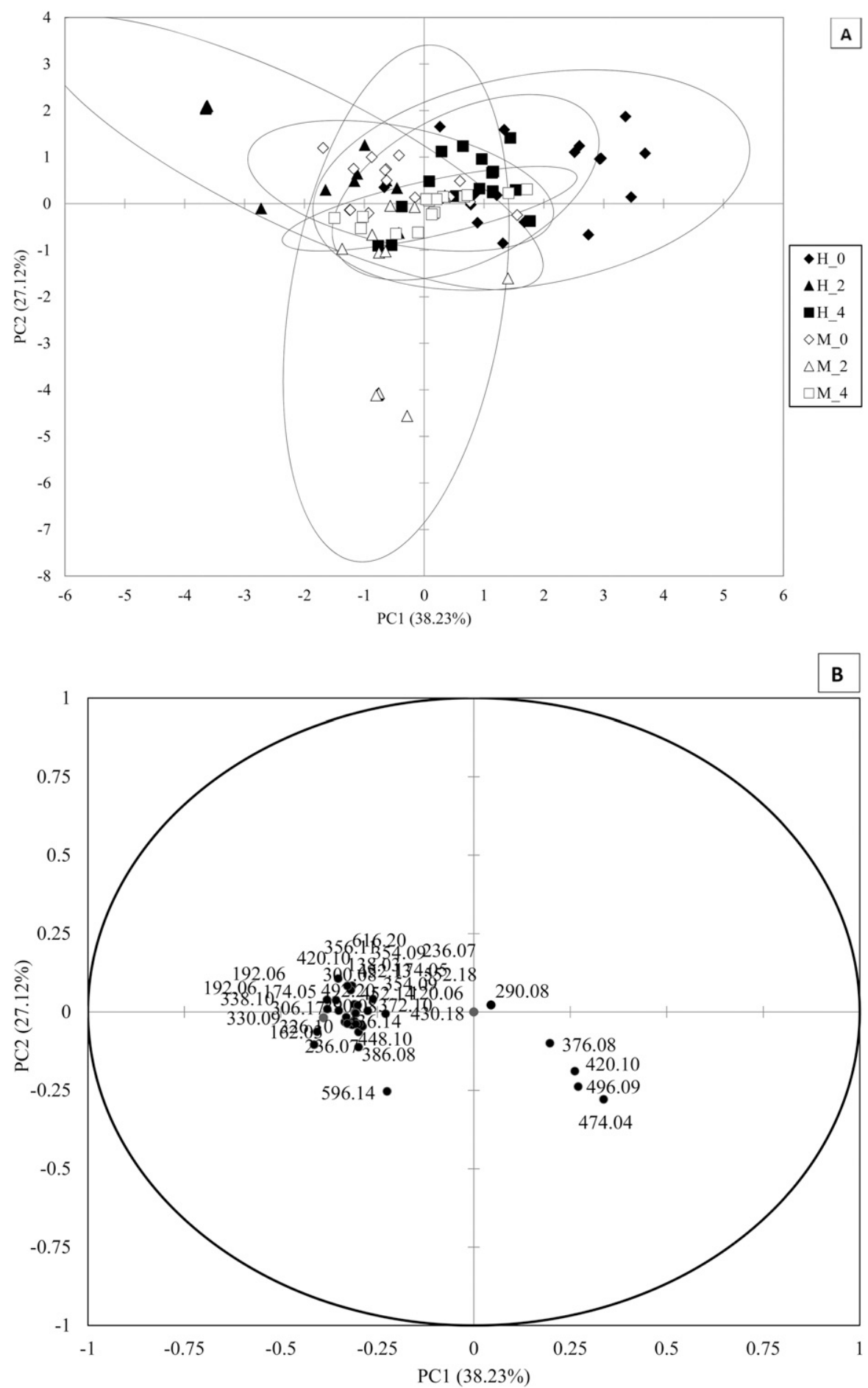

Fig. 1. (A) Score plot for juice samples derived from machine- ("M_") or handharvested ("H_") 'Brown Snout' cider apples ambient stored [ $\left.56{ }^{\circ} \mathrm{F}\left(13.3{ }^{\circ} \mathrm{C}\right)\right]$ postharvest 0,2 , or 4 weeks (“_0”, “_2”, or “_4”) in 2016. Ellipses represent the $\mathbf{9 5 \%}$ confidence level for each sample class; ellipses that overlap are not significantly different from one another $(P<0.05)$. (B) Loading plot for discriminant analysis showing accurate mass data for compounds associated with each of the juice types. Mass data are truncated to two places after the decimal point, and retention times are not shown for clarity. Principal component 1 (PC1) and 2 (PC2), uncorrelated variables, capture the greatest variation in the dataset. 
phenolics, and total tannins. These data were analyzed by two-way analysis of variance followed by all possible pairwise comparisons using Tukey's honestly significant difference test, significance defined at the $5 \%$ level. UHPLC/QTOF-MS results were processed using MassHunter (version 7.0; Agilent Technologies) and Mass Profiler Professional (MPP version 13.1.1; Agilent Technologies) software packages. The Molecular Feature Extractor algorithm in MassHunter was used to identify potential peaks; a minimum peak count of 8000 was used for juice and 14,000 for cider, and peaks were aligned across all samples using the data alignment package in MPP. The aligned peaks were then screened for presence across replicates and for minimum peak abundance. The screened set of entities (accurate mass and associated retention time) was subsequently evaluated using the Metlin Tandem Mass Spectrometry database (Scripps Research, 2019) to make tentative identifications for the entities. For both juice and cider, entities that were identified as phenolic compounds (36 for juice and 30 for cider) were selected for statistical analysis. These entities were used to generate a discriminant analysis to evaluate the relationships among sample types, to show statistical differences among samples where such differences exist, and to identify entities correlated with different sample classes. Discriminant analysis was done using XLSTAT 2018 (AddinSoft, New York, NY).

\section{Results}

QUALITY CHARACTERISTICS ANALYSIS. Interaction of the main factors, harvest method and duration of ambient storage, were found to be nonsignificant $[P>0.05$ (data not shown)] for all parameters measured on juice and cider samples. Variation due to harvest method was found to be nonsignificant for all parameters measured on juice and cider samples (data not shown). The $\mathrm{SG}, \mathrm{pH}$, and TA of juice samples significantly differed due to duration of ambient storage $[P=0.01, P=0.04$, and $P=$ 0.01 , respectively (Table 1$)]$. SG on average increased over time, from $( \pm \mathrm{SE})$ $1.054 \pm 0.001$ at 0 weeks to $1.059 \pm$ 0.001 at 4 weeks ambient storage. $\mathrm{pH}$ on average decreased from 2 to 4 weeks ambient storage $(4.06 \pm 0.01$ and $4.01 \pm 0.01$, respectively). TA on average increased from 2 to 4 weeks ambient storage $(0.35 \% \pm 0.01 \%$ and $0.38 \% \pm 0.01 \%$, respectively). The titratable tannin content of juice samples did not differ due to harvest method or duration of storage, and was $0.19 \% \pm 0.01 \%$ on average. The average $\mathrm{ABV}$ of juice samples was
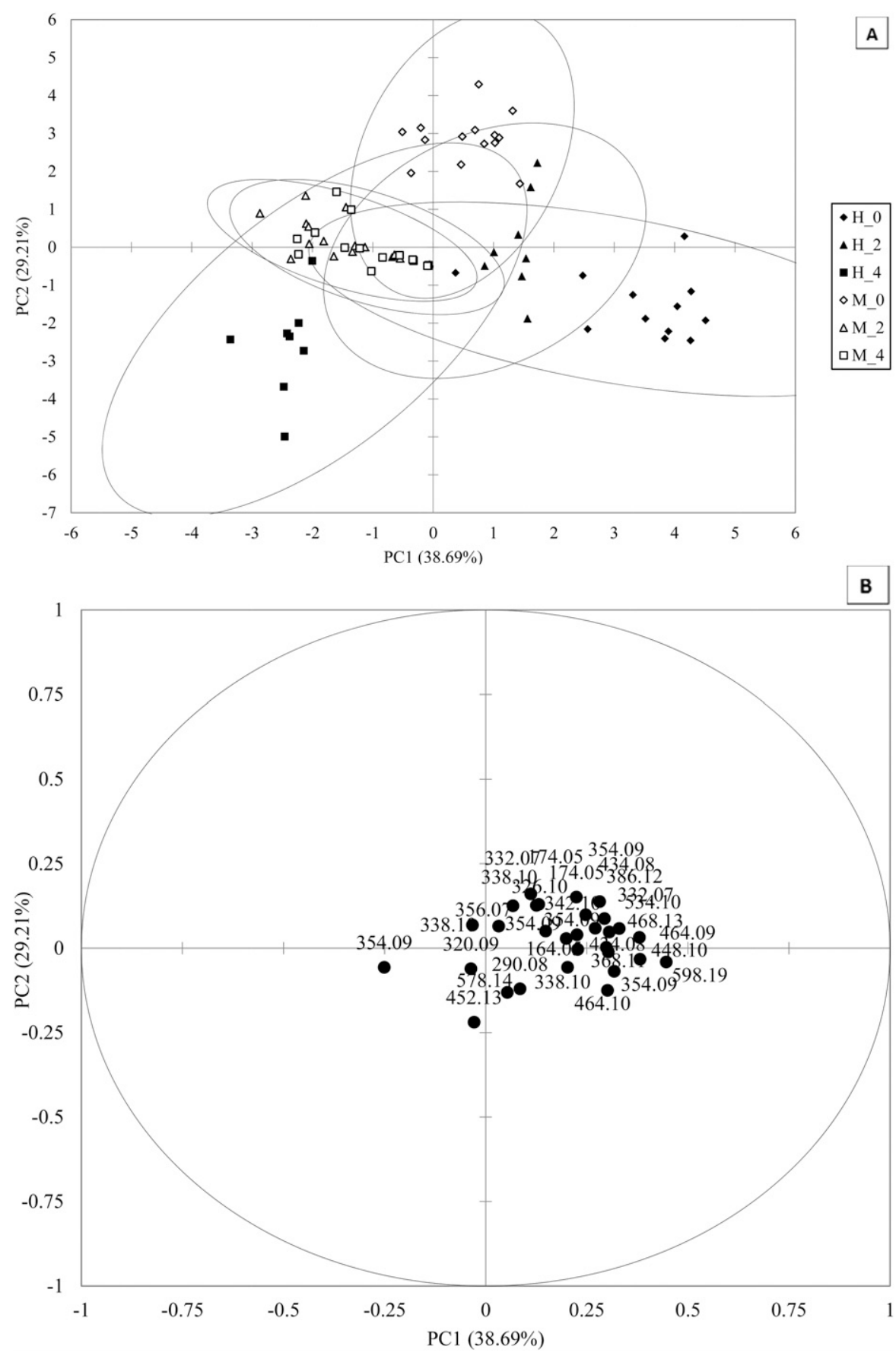

Fig. 2. (A) Score plot for cider samples derived from machine- ("M_") or handharvested ("H_.") 'Brown Snout' apples ambient stored [56 $\left.{ }^{\circ} \mathrm{F}\left(13 .{ }^{\circ} \mathrm{C}\right)\right]$ postharvest 0,2 , or 4 weeks (“_0", “_2", or “_4") in 2016. Ellipses represent the $\mathbf{9 5 \%}$ confidence level for each sample class; ellipses that overlap are not significantly different from one another $(P<0.05)$. (B) Loading plot for discriminant analysis showing accurate mass data for compounds associated with each of the cider types. Mass data are truncated to two places after the decimal point, and retention times are not shown for clarity. Principal component 1 (PC1) and 2 (PC2), uncorrelated variables, capture the greatest variation in the dataset. 
measured to be $0 \%$ pre-fermentation, as expected. The ABV of cider samples differed due to duration of storage $(P=0.02)$. ABV on average increased from 0 to 4 weeks ambient storage $(5.39 \% \pm 0.19 \%$ and $6.14 \% \pm$ $0.16 \%$, respectively). The $\mathrm{SG}, \mathrm{pH}$, and TA of cider samples did not significantly differ due to harvest method or duration of storage, and were $0.999 \pm 0.000,3.52 \pm 0.01$, and $0.63 \% \pm 0.02 \%$ on average, respectively. This result was expected, as these three parameters were artificially adjusted to provide for a controlled fermentation. The titratable tannin content of cider samples did not differ due to harvest method or duration of storage, and was $0.19 \% \pm$ $0.01 \%$ on average.

TOTAL PHENOLICS AND TOTAL TANNINS ANALYSIS. Interaction of the main factors, harvest method and duration of ambient storage, were found to be nonsignificant $[P>0.05$ (data not shown)] for all parameters measured on juice and cider samples. Variation due to duration of ambient storage was also found to be nonsignificant for all parameters measured on juice and cider samples (data not shown). Total tannins and nontannin phenolic levels in juice samples significantly differed due to harvest method $(P<0.0001$ and $P=$ 0.04, respectively). Machine-harvested juice samples had lower levels $\left(231 \pm 36 \mathrm{mg} \cdot \mathrm{L}^{-1} \mathrm{CE}\right)$ of total tannins and higher levels $\left(1184 \pm 93 \mathrm{mg} \cdot \mathrm{L}^{-1}\right.$ $\mathrm{CE}$ ) of nontannin phenolics than hand-harvested juice samples [420 \pm 14 and $996 \pm 75 \mathrm{mg} \cdot \mathrm{L}^{-1} \mathrm{CE}$, respectively (Table 2)]. Total phenolics in juice samples did not significantly differ due to harvest method (1415 \pm $\left.98 \mathrm{mg} \cdot \mathrm{L}^{-1} \mathrm{CE}\right)$. Total tannins, nontannin phenolics, and total phenolics in cider samples did not significantly differ due to harvest method (203 \pm $22,1229 \pm 74$, and $1431 \pm 73 \mathrm{mg} \cdot \mathrm{L}^{-1}$ $\mathrm{CE})$.

U H P L C / Q T O F - M S ANALYSIS. For the juice samples, the first two components of the discriminant analysis described $65.35 \%$ of the variation observed among the samples (Fig. 1A). For the cider samples, the first two components of the discriminant analysis described $67.90 \%$ of the variation observed among the samples (Fig. 2A). Discriminant analysis is used here to show statistical differences among samples where such differences exist. The ellipses in the discriminant analysis represent the $95 \%$ confidence interval for each of the sample types (e.g., different

juice treatments). In instances where the ellipses of two sample classes overlap, the sample types are not significantly different $(P<0.05)$. Where the
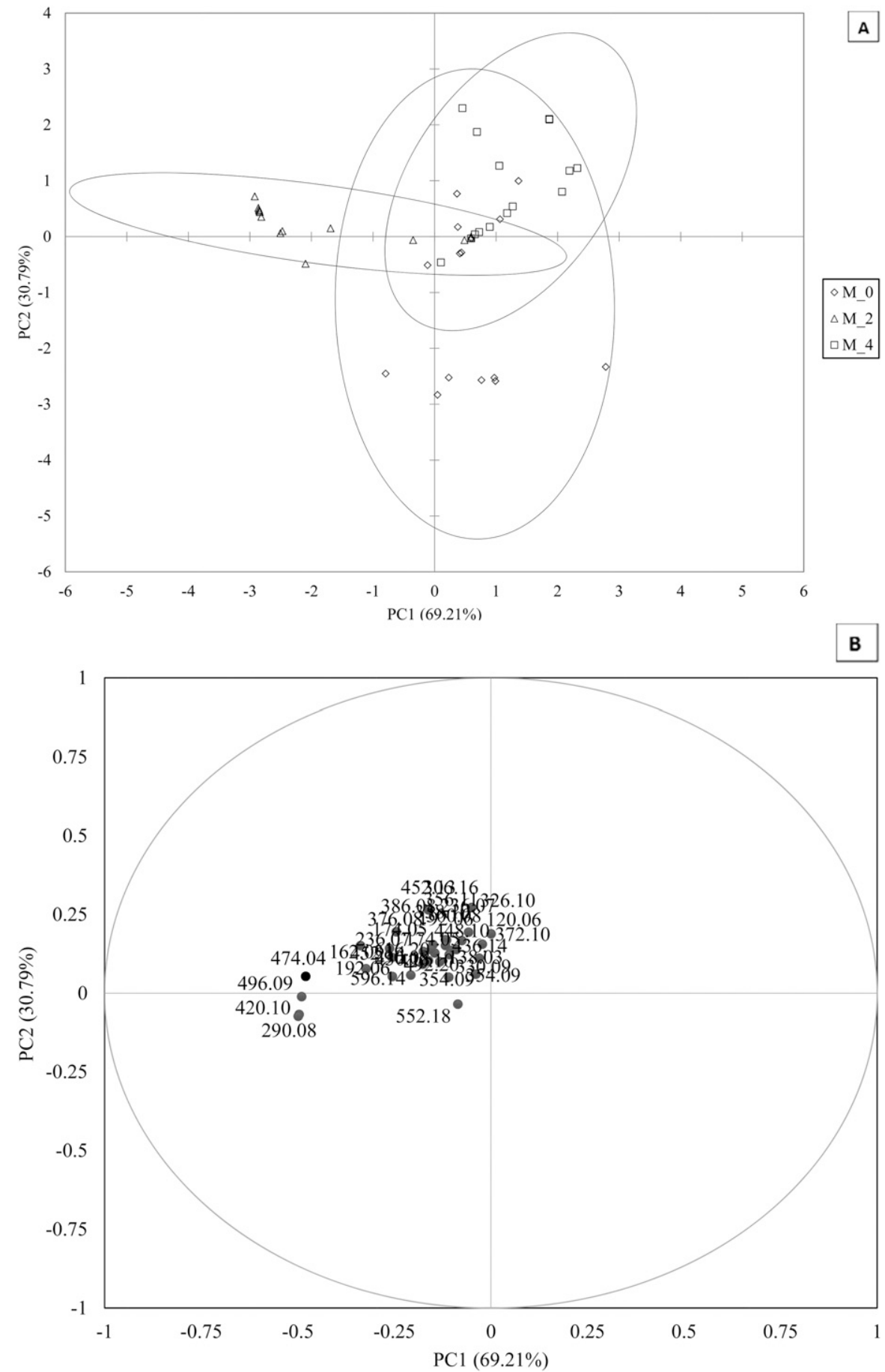

Fig. 3. (A) Score plot for juice samples derived from machine- ("M_") harvested 'Brown Snout' apples ambient stored $\left[56^{\circ} \mathrm{F}\left(13.3^{\circ} \mathrm{C}\right)\right]$ postharvest 0,2 , or 4 weeks (“_0", “_2", or “_4") in 2016. Ellipses represent the $95 \%$ confidence level for each sample class; ellipses that overlap are not significantly different from one another $(P<0.05)$. (B) Loading plot for discriminant analysis showing accurate mass data for compounds associated with each of the juice types. Mass data are truncated to two places after the decimal point, and retention times are not shown for clarity. Principal component 1 (PC1) and 2 (PC2), uncorrelated variables, capture the greatest variation in the dataset. 
ellipses of the sample classes overlap for both the juice and the cider treatments, no significant separation of samples due to harvest method was apparent. However, there did appear to be some interaction of harvest method and duration of ambient storage. Machine-harvested juice and cider samples from fruit stored at ambient temperature before processing exhibited a trend toward separation, with samples stored for 0 weeks separating partially from samples made from fruit stored for 2 or 4 weeks (Figs. 3A and 4A).

These discriminant analyses were based on 36 phenolic compounds for juice and 30 phenolic compounds for cider that resulted from the screening of aligned chromatographic peaks; the correlation of these compounds with the first two dimensions in the discriminant analysis are shown in the variable loadings plots (Figs. $1 \mathrm{~B}-4 \mathrm{~B}$ ). The mass data shown in these plots is truncated and the retention times are not shown as well, for clarity in these plots. In the case of juice samples (Fig. 1B), there are only five compounds positively associated with the first dimension; juice samples from hand-harvested fruit and processed immediately (H_0) are the samples most strongly correlated with the positive side of this dimension. For ciders (Fig. 2B), most of the phenolic compounds are positively associated with the first dimension; ciders made from hand-harvested fruit held for 0 and 2 weeks, along with machine harvest fruit held for 0 weeks are positively associated with this dimension. The ciders made from handharvested fruit held for 4 weeks and machine-harvested fruit held for 2 or 4 weeks are negatively correlated with the first dimension and are characterized by lower levels of these compounds.

The compound lists (Tables 3 and 4) do not reflect a comprehensive list of phenolic compounds present in these samples and are used primarily as a means for determining the relationships among the sample classes in the study. Nevertheless, most of the phenolic compounds used for discriminating between sample class were tentatively identified through comparison of accurate mass and relative retention time results with previously reported values for polyphenols in apple and pear (Pyrus
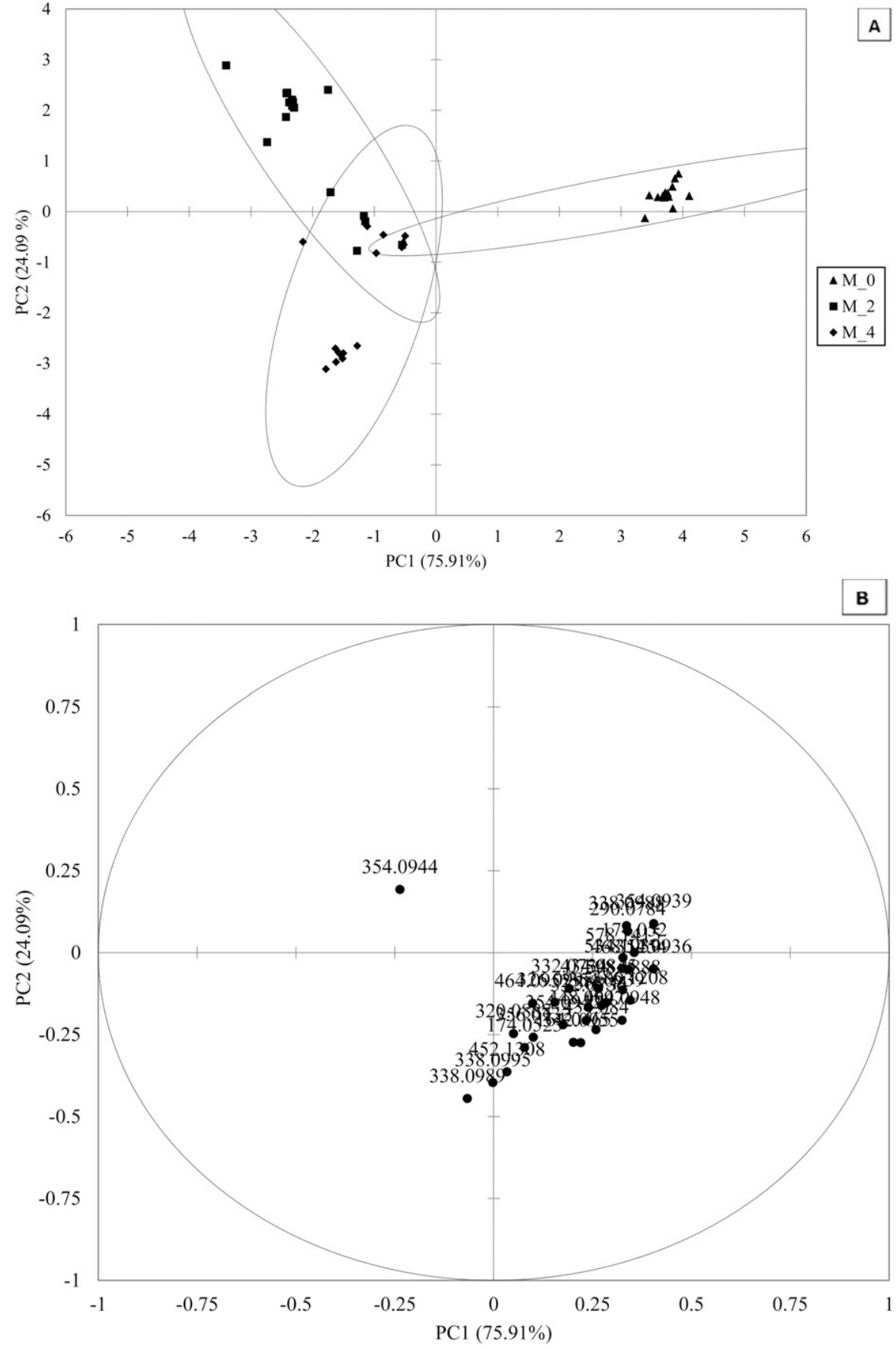

Fig. 4. (A) Score plot for cider samples derived from machine- ("M_") harvested 'Brown Snout' apples ambient stored $\left[56^{\circ} \mathrm{F}\left(13.3^{\circ} \mathrm{C}\right)\right]$ postharvest 0,2 , or 4 weeks (“_0”, “_2”, or “_4”) in 2016. Ellipses represent the 95\% confidence level for each sample class; ellipses that overlap are not significantly different from one another $(P<0.05)$. (B) Loading plot for discriminant analysis showing accurate mass data for compounds associated with each of the cider types. Mass data are truncated to two places after the decimal point, and retention times are not shown for clarity. Principal component 1 (PC1) and 2 (PC2), uncorrelated variables, capture the greatest variation in the dataset.

communis) fruit, juices, and related products (Bars-Cortina et al., 2017; Kolniak-Ostek and Oszmiański, 2015; Lee et al., 2017; Navarro et al., 2018; Ramirez-Ambrosi et al.,
2013; Raudone et al., 2016; Verdu et al., 2013). In some instances, the tentative identifications are from the Metlin Tandem Mass Spectrometry database (Scripps Research, 2019). 
Table 3. Neutral mass [M] and retention time (RT) of 36 phenolic compounds tentatively identified (ID) in juice samples derived from machine- and hand-harvested 'Brown Snout' cider apples ambient stored $\left[56^{\circ} \mathrm{F}\left(13.3{ }^{\circ} \mathrm{C}\right)\right]$ postharvest up to 4 weeks in Washington in 2016, unknown ID listed for entities that did not match previously reported values for polyphenols in apple and pear fruits, juices, or related products.

\begin{tabular}{|c|c|c|c|}
\hline$[\mathbf{M}]$ & $\mathrm{RT}(\mathrm{s})$ & ID & References \\
\hline 120.0572 & 2.83 & Acetophenone & Metlin $^{\mathrm{z}}$ \\
\hline 138.0312 & 2.82 & Salicylic acid & Lee et al. (2017) \\
\hline 162.0311 & 2.24 & Hydroxycoumarin & Metlin \\
\hline 174.052 & 2.58 & Shikimic acid & Navarro et al. (2018) \\
\hline 174.0524 & 2.82 & Shikimic acid & Navarro et al. (2018) \\
\hline 192.0621 & 2.23 & Quinic acid & Bars-Cortina et al. (2017) and Raudone et al. (2016) \\
\hline 236.0676 & 1.90 & Unknown & \\
\hline 290.078 & 2.02 & Catechin & $\begin{array}{l}\text { Kolniak-Ostek and Oszmiański (2015), Ramirex- } \\
\text { Ambrosi et al. (2013), Thompson-Witrick et al. } \\
\text { (2014), and Verdu et al. (2013) }\end{array}$ \\
\hline 290.0781 & 2.85 & Epicatechin & $\begin{array}{l}\text { Ramirex-Ambrosi et al. (2013), Thompson-Witrick et al. } \\
\text { (2014), and Verdu et al. (2013) }\end{array}$ \\
\hline 330.0942 & 1.34 & Methoxybenzoic acid glucoside & Metlin \\
\hline 338.0992 & 2.82 & Coumaroyl quinic acid & $\begin{array}{l}\text { Kolniak-Ostek and Oszmiański (2015), Ramirex- } \\
\text { Ambrosi et al. (2013), and Verdu et al. (2013) }\end{array}$ \\
\hline 354.094 & 2.39 & $\begin{array}{l}\text { Caffeoyl quinic acid (chlorogenic } \\
\text { acid isomer) }\end{array}$ & $\begin{array}{l}\text { Kolniak-Ostek and Oszmiański (2015) and Verdu et al. } \\
(2013)\end{array}$ \\
\hline 354.0945 & 2.21 & $\begin{array}{l}\text { Caffeoyl quinic acid (chlorogenic } \\
\text { acid isomer) }\end{array}$ & $\begin{array}{l}\text { Kolniak-Ostek and Oszmiański (2015) and Verdu et al. } \\
(2013)\end{array}$ \\
\hline 356.1095 & 3.27 & Feruloyl glucose & Ramirex-Ambrosi et al. (2013) \\
\hline 372.1047 & 0.64 & Dihydroferuloyl glucuronide & Metlin \\
\hline 376.076 & 2.24 & Unknown & \\
\hline 386.0835 & 0.84 & Feruloyl galacturate & Metlin \\
\hline 474.0424 & 2.21 & Unknown & \\
\hline 492.2014 & 4.25 & Isolariciresinol arabinoside & Metlin \\
\hline 496.0885 & 2.82 & Digalloyl quinic acid & Metlin \\
\hline 552.1821 & 3.36 & Resvervatrol diglucoside & Metlin \\
\hline 596.1361 & 2.66 & Quercetin arabinosyl glucose & Navarro et al. (2018) \\
\hline 616.2026 & 3.52 & Unknown & \\
\hline
\end{tabular}

${ }^{\mathrm{z}}$ Metlin Tandem Mass Spectrometry database (Scripps Research, 2019).

In instances in which the entity (accurate mass and associated retention time) did not match either previously reported compounds in apples or pears or did not have a mass match in Metlin, it is listed in Tables 3 or 4 as unknown.

\section{Discussion}

Quality characteristics of juice and cider samples did not differ due to harvest method, but there was an effect of ambient storage time, as was observed with the results of the UHPLC/QTOF-MS analysis. The SG and TA of juice samples increased, whereas the $\mathrm{pH}$ of juice samples decreased over time. Given these compositional changes, the fruit most likely underwent dehydration in ambient storage (or as commonly termed "sweating"). Further ripening of the harvested fruit may also explain the increase in SG, as starch converted to soluble sugars; but with ripening one would expect TA to decrease and
$\mathrm{pH}$ to increase, opposite of what was observed in this study. The ABV of cider samples correspondingly increased with duration of ambient storage, a higher initial SG (i.e., sugar content) providing for a higher potential alcohol production by yeast.

Total phenolics and total tannins of juice samples did not differ due to duration of ambient storage time, but there was an effect of harvest method. The total phenolics of machine- and hand-harvested samples were similar, 


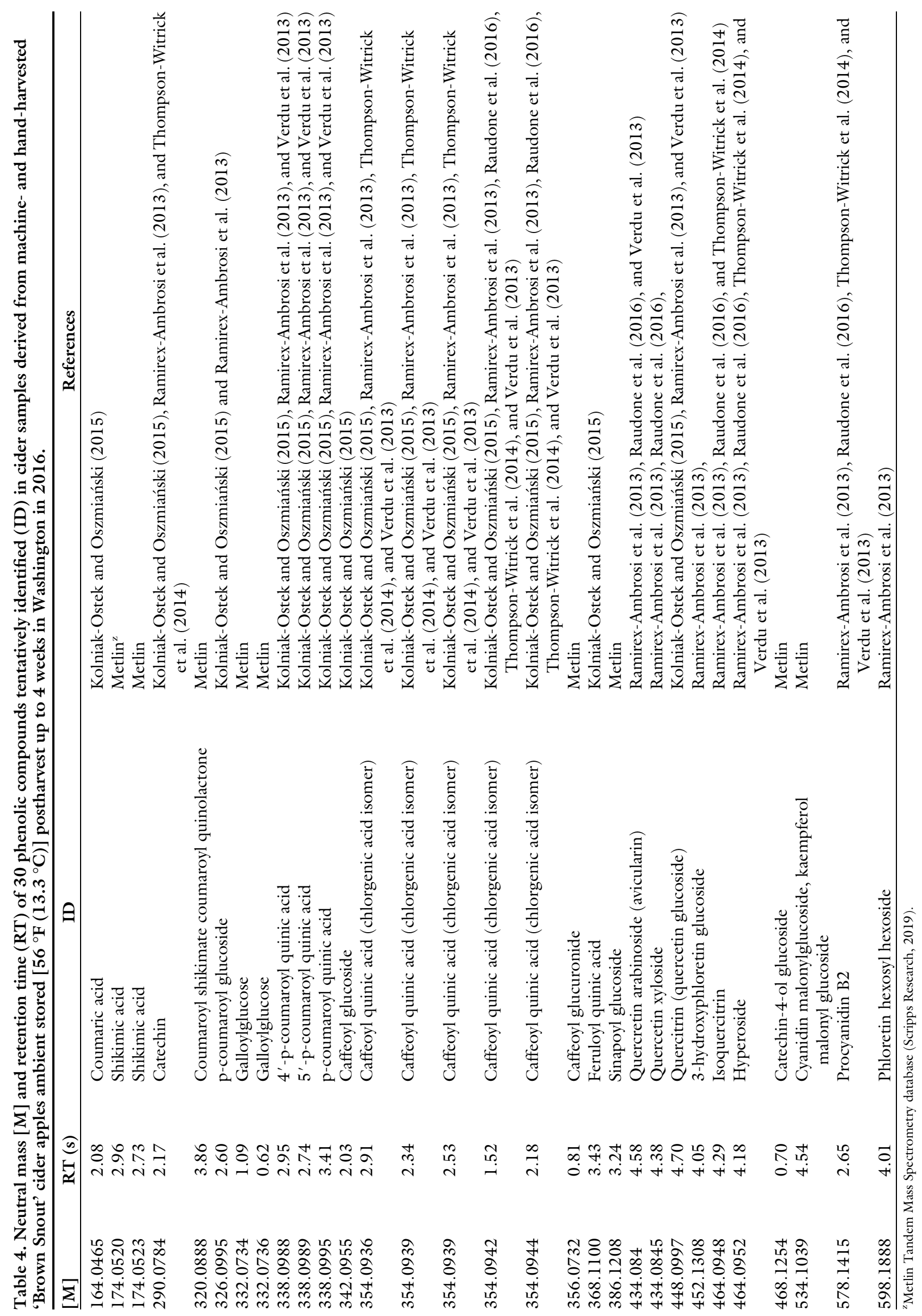

Horllechnology · August 2019 29(4) 
but the total tannins were lower, and conversely nontannin phenolics were higher for machine-harvested samples than hand-harvested samples. Compositional changes imparted by machine harvest most likely do not result in an absolute loss of tannins, but rather a conversion to a form not detected by the protein precipitation assay. The total phenolics and total tannins of cider samples did not significantly differ due to either of the main factors evaluated. The chemical differences measured in the juice were minimized from fermentation to bottling, and the total tannins of machine- and hand-harvested cider samples were on average half of the hand-harvested juice samples. The finding of a difference in total tannins of juice samples due to harvest method by the protein precipitation assay but not the redox titration assay (Harbertson et al., 2003; Löwenthal, 1877), demonstrates the complex chemistry of phenolics and the importance of understanding what an assay is specifically measuring. A reduction in total tannins of a cider would be undesired because these protein precipitation compounds underlie the traditional sensory characteristics of cider, predominantly astringency and bitterness. This difference in results between the two assays also supports the need for development of a new cider apple classification system that more accurately reflects the phenolic profile of cultivars in the context of astringency and bitterness. This new American classification system should be based on a subset of phenolic compounds that cider researchers agree are primarily responsible for eliciting the sensory perceptions of astringency and bitterness with separate category thresholds for each perception.

Modification of pressing methodology to maximize extraction of phenolic compounds from machineharvested fruit or addition of exogenous phenolic compounds to juice could serve to minimize the observed reductions in juice total tannins. At the same time, using the fermentation protocol pursued in this study, it was demonstrated that the total tannins of cider derived from machine- and hand-harvested fruit was not significantly different. Despite the difference in total tannins in the raw product, the total tannins in the final product were measured to be the same among harvest methods. Given that no standard fermentation protocol is followed by all cider makers, even within one style of cider, further research involving multiple fermentation protocols should be pursued to confirm the observations in this study. The UHPLC/QTOF-MS results of this study can provide baseline data for these additional studies.

Total phenolics and total tannins did not differ due to ambient storage time; however, growers should avoid ambient storage of machine-harvested cider apples given the potential yield losses demonstrated by Alexander et al. (2016). Overall, this study has complemented previous yield and sensory evaluation assessments in demonstrating cider made from machine-harvested cider apples is of equal quality as cider made from hand-harvested fruit.

\section{Literature cited}

Alexander, T.R., J. King, E. Scheenstra, and C.A. Miles. 2016. Yield, fruit damage, yield loss and juice quality characteristics of machine and hand-harvested 'Brown Snout' specialty cider apple stored at ambient conditions in northwest Washington. HortTechnology 26:614619.

Alexander, T.R., C.F. Ross, E.A. Walsh, and C.A. Miles. 2018. Sensory comparison of ciders produced from machine- and hand-harvested 'Brown Snout' specialty cider apples stored at ambient conditions in northwest Washington. HortTechnology 28:35-43.

Alwood, W.B. 1903. A study of cider making. U.S. Dept. Agr., Bur. Chem. Bul. No. 71 .

Barker, B.T.P. 1903. Classification of cider apples. Natl. Fruit Cider Inst. Long Ashton Res. Sta., Bristol, UK.

Bars-Cortina, D., A. Macia, I. Iglesias, M. Paz Romero, and M.J. Motilva. 2017. Phytochemical profiles of new red-fleshed apple varieties compared with traditional and new white-fleshed varieties. J. Agr. Food Chem. 65:1684-1696.

Blanpied, G.D. and K.J. Silsby. 1992. Predicting harvest date windows for apples. Cornell Info. Bul. No. 221.

Chu, C.I.G. and K.R. Wilson. 2000. Evaluating maturity of 'McIntosh' and 'Red Delicious' apples. Ontario Ministry Agr. Food Rural Affairs Publ. Order No. 00-025. 22 Mar. 2016. <http://www. omafra.gov.on.ca/english/crops/facts/ 00-025.htm>.

Cliff, M., M.C. Dever, and R. Gayton. 1991. Juice extraction process and apple cultivar influences on juice properties. J. Food Sci. 56:1614-1627.

Ewing, B., G.M. Peck, S. Ma, A.P. Neilson, and A.C. Stewart. 2019. Management of apple maturity and postharvest storage conditions to increase polyphenols in cider. HortScience 54:143148.

Galinato, S.P., C.A. Miles, and T.R. Alexander. 2016. Feasibility of different harvest methods for cider apples: Case study for western Washington. Washington State Univ. Ext. Publ. TB32E.

Guyot, S., N. Marnet, P. Sanoner, and J.-F. Drilleau. 2003. Variability of the polyphenolic composition of cider apple (Malus domestica) fruits and juices. J. Agr. Food Chem. 51:6240-6247.

Harbertson, J.F., E.A. Picciotto, and D.O. Adams. 2003. Measurement of polymeric pigments in grape berry extracts and wines using a protein precipitation assay combined with bisulfite bleaching. Amer. J. Enol. Viticult. 54:301306.

Joslyn, M.A. and J.L. Goldstein. 1964. Astringency of fruits and fruit products in relation to phenolic content. Adv. Food Res. 13:179-217.

Kolniak-Ostek, J. and J. Oszmiański. 2015. Characterization of phenolic compounds in different anatomical pear (Pyrus communis L.) parts by ultra-performance liquid chromatography photodiode detector-quadrupole/time of flightmass spectrometry (UPLC-PDA-Q/TOFMS). Intl. J. Mass Spectrom. 392:154163.

Koyama, N. and K. Kurihara. 1972. Mechanism of bitter taste reception: Interaction of bitter compounds with monolayers of lipids from bovine circumvallate papillae. Biochimica et Biophysica Acta Biomembranes 288:22-26.

Lea, A.G.H. 1990. Bitterness and astringency: The procyanidins of fermented apple ciders, p. 123-143. In: R.L. Rousseff (ed.). Bitterness in foods and beverages. Elsevier, Oxford, England.

Lea, A.G.H. and G.M. Arnold. 1978. The phenolics of cider: Bitterness and astringency. J. Sci. Food Agr. 29:478-483.

Lea, A.G.H. and C.F. Timberlake. 1978. The phenolics of cider: Effect of processing conditions. J. Sci. Food Agr. 29:484492.

Lee, J., B.L.S. Chan, and A.E. Mitchell. 2017. Identification/quantification of 
free and bound phenolic acids in peel and pulp of apples (Malus domestica) using high resolution mass spectrometry (HRMS). Food Chem. 215:301-310.

Löwenthal, J. 1877. Uber die bestimmung des gerbstoffs. Z. Anal. Chem. $16: 33-48$.

Miles, C.A. and J. King. 2014. Yield, labor, and fruit and juice quality characteristics of machine and hand-harvested 'Brown Snout' specialty cider apple. HortTechnology 24:519-526.

Moulton, G.A. and J. King. 2008. Fruit handbook for western Washington. Washington State Univ. Ext. Publ. EB0937.

Navarro, M., I. Moreira, E. Arnaez, S. Quesada, G. Azofeifa, F. Vargas, D. Alvarado, and P. Chen. 2018. Polyphenolic characterization and antioxidant activity of Malus domestica and Prunus domestica cultivars from Costa Rica. Foods 7(2):15.

Nicolas, J.J., F.C. Richard-Forget, P.M. Goupy, M.J. Amiot, and S.Y. Aubert. 1994. Enzymatic browning reactions in apple and apple products. Crit. Rev. Food Sci. Nutr. 34:109-157.

Ramirez-Ambrosi, M., B. Abad-Garcia, M. Viloria-Bernal, S. Garmon-Lobato, L.A. Berrueta, and B. Gallo. 2013. A new ultrahigh performance liquid chromatography with diode array detection coupled to electrospray ionization and quadrupole time-of-flight mass spectrometry analytical strategy for fast analysis and improved characterization of phenolic compounds in apple products. J. Chromatography 1316:78-91

Raudone, L., R. Raudonis, M. Liaudanskas, J. Viskelis, A. Pukalskas, and V. Janulis. 2016. Phenolic profiles and contribution of individual compounds to antioxidant activity of apple powders. J. Food Sci. 81:C1055-C1061.

Renard, C.M., A. Baron, S. Guyot, and J-F. Drilleau. 2001. Interactions between apple cell walls and native apple polyphenols: Quantification and some consequences. Intl. J. Biol. Macromol. 29:115-125.

Renard, C.M.G.C., J.-M. Le Quere, R. Bauduin, R. Symoneaux, C. Le Bourvellec, and A. Baron. 2011. Modulating polyphenolic composition and organoleptic properties of apple juices by manipulating the pressing conditions. Food Chem. 124:117-125.

Sanoner, P., S. Guyot, N. Marnet, D. Molle, and J.-F. Drilleau. 1999. Polyphenol profiles of French cider apple varieties (Malus domestica sp.). J. Agr. Food Chem. 47:4847-4853.

Sataque, E.Y. and G. Wosiacki. 1987. Caracterização da polifenoloxidase de maçã (variedade Gala). Arq. Biol. Tecnol. 30:287-299.

Scripps Research. 2019. Metlin tandem mass spectrometry database. 5 Mar. 2019. $<$ https://metlin.scripps.edu/landing page.php?pgcontent $=$ mainPage $>$.

Shahidi, F. and M. Naczk. 1995. Food phenolics-sources, chemistry, effect, applications. Technomic Publ., Lancaster, PA.

Soest, P.J. 1994. Nutritional ecology of the ruminant. Cornell Univ. Press, Ithaca, NY.

Tavernier, J. and P. Jacquin. 1949. Etude technologique de variétés de pomme à cidre. Revue interne du Groupement National Interprofessionnel des fruit à cidre et dérivés 1:36.
Thilmany, D. 2001. Farm labor trends and management in Washington State. J. Agribusiness 19(Spring):1-15.

Thompson-Witrick, K.A., K.M. Goodrich, A.P. Neilson, E.K. Hurley, G.M. Peck, and A.C. Stewart. 2014. Characterization of the polyphenol composition of 20 cultivars of cider, processing, and dessert apples (Malus $\times$ domestica Borkh.) grown in Virginia. J. Agr. Food Chem. 62:1018110191.

Tomas-Barberan, F.A. and C. AndresLacueva. 2012. Polyphenols and health: Current state and progress. J. Agr. Food Chem. 60:8773-8775.

U.S. Department of Agriculture. 2013. Web soil survey. 17 Sept. 2013. <http:// websoilsurvey.nrcs.usda.gov>.

Verdu, C.F., J. Gatto, I. Freuze, P. Richomme, F. Laurens, and D. Guilet. 2013. Comparison of two methods, UHPLC-UV and UHPLC-MS/MS, for the quantification of polyphenols in cider apple juices. Molecules 18:10213-10227.

Washington State University. 2013. Crop protection guide for tree fruits in Washington. Washington State Univ. Ext. Publ. EB0419.

Whiting, G.C. 1975. Some biological and flavour aspects of lactic acid bacteria in ciders and other alcoholic beverages, p. 69-85. In: J.G. Carr, C.V. Cutting, and G.C. Whiting (eds.). Lactic acid bacteria in beverages and food. Academic Press, London, England.

Zimmerman, A., G. Moulton, and C.A. Miles. 2017. Fermentation protocol at WSU Mount Vernon NWREC for production of varietal ciders. 3 May 2017. $<\mathrm{ht} \mathrm{t}$ : : / / ext l 00 . w s u . ed u / maritimefruit/wpcontent/uploads / sites/36/2015/04/CiderFermentation Protocol2015.pdf>. 